Bayero Journal of Pure and Applied Sciences, 11(1): 238 - 243

ISSN $2006-6996$

\title{
PATHOPHYSIOLOGY AND MANAGEMENT OF PARKINSON DISEASE: A REVIEW
}

\author{
${ }^{*}$ Abdullahi Samaila ${ }^{1}$ and Hayatudeen M. ${ }^{2}$ \\ 1Department of Pharmacology, College of Medical Sciences, Umaru Musa Yar'adua \\ University, Katsina, Nigeria. P.M.B. 2218. \\ 2 Department of Microbiology, Umaru Musa Yar'adua University, Katsina, Nigeria. \\ *Corresponding Author: abuuismaeel@gmail.com, Mobile: Tel: 08031817444.
}

\begin{abstract}
Parkinson's disease is a neurological disorder that is characterized by the typical motor symptoms of Parkinsonism associated with Lewy bodies and loss of dopaminergic neurons within the substantia nigra. It is associated with fluctuations of motor and non-motor symptoms, dyskinesia and psychosis. Parkinson's disease affects almost $1 \%$ of individuals older than 60 years. The incidence is higher in Europe, North and South America compared to Africa. Male to female ratio is 3:2. The aim of this review is to describe the pathophysiology and management of Parkinson's disease. Aetiological risk factors of Parkinson's disease were theorised to be due to genetic and environmental factors. Some of the environmental risk factors include chronic pesticide exposure, prior head injury etc. while some of the genetic risk factors include beta-glucocerobrosidase gene (GBA), leucinerich repeat kinase-2 (LRRK2) and synuclein alpha (SNCA) genes. Parkinson disease is mainly a disorder of the basal ganglia, a group of nuclei located at the base of the forebrain. There are two main neuropathological discoveries related to the disease: the damage of pigmented dopaminergic neurons in the substantia nigra pars compacta (SNpc), and the appearance of Lewy bodies that leads to the formation of Lewy neurites, which are typical pathologic outcomes in Parkinson disease. The management comprises of diagnosis and treatment. The diagnosis is mainly clinical while the treatment is essentially medical which include. Levodopa/carbidopa administration in combination for control of motor symptoms.

Keywords; Parkinson's disease, Substantia nigra, Lewy bodies, levodopa, dopaminergic neurons.
\end{abstract}

\section{INTRODUCTION}

James Parkinson initially described Parkinson disease as the "shaking palsy" in the year 1817 (Chauhan and Jeans, 2015; Fernandez, 2012). Parkinson's disease is a neurological disorder with emerging layers of complication. It is recognised by the typical motor symptoms of Parkinsonism associated with Lewy bodies and loss of dopaminergic neurons within the substantia nigra. Parkinsonism is a clinical/neurological syndrome depicted by bradykinesia (that is difficulty or slowness in initiating movement) plus one or more of Muscle rigidity, tremor at rest and postural instability. The development of these motor features might take between twelve to fourteen (12 - 14) years approximately (Postuma et al., 2012). The complication of Parkinson's disease in terms of how it progresses is accompanied by clinical challenges, which include difficulty in making definitive diagnosis at the initial phases of the disease and problems with managing the symptoms of the disease at late stages. Moreover, no specific treatments slow the neurodegenerative process (Kalia and Lang, 2015). Parkinson's disease affects almost $1 \%$ of individuals older than 60 years. The incidence was estimated to be around 4.5-21 cases per 100,000 populations per year, and prevalence of nearly 120 cases per 100,000 population (Hauser et al., 2014). The incidence and prevalence rise almost exponentially with age and peak after eighty years of age (Driver et al., 2009; Pringsheim et al., 2014). The incidence is higher in Europe, North and South America compared to African, Asian and Arabian countries. More common in over 60s and uncommon in under 40s. (Kalia, \& Lang, 2015; Hauser et al., 2014). Male to female ratio is 3:2 (De Lau and Breteler, 2006).

Okubadejo et al., (2010), detected 124 patients with Parkinsonism out of which 98 (79\%) already developed Parkinson's disease among southwestern Nigerian population. Age at onset is averagely 61.5 years. Male to female ratio is 3.3:1. Co-morbidities such as hypertension and diabetes are associated with Parkinson disease in Nigeria. 
The clinical profile of Parkinson disease in Nigerian population is identical to that of other population. It is anticipated that the number of people with Parkinson's disease will increase by the year 2030 (Driver et al., 2009). Parkinson disease is associated with morbidity and mortality. Some of the predictors of mortality include age at onset, severity of motor symptoms, psychotic symptoms and dementia (Forsaa et al., 2010). The objective of this work is to present a reviewed update on pathophysiology and medical management of Parkinson's disease as a chronic neurodegenerative disorder.

\section{Aetiological Risk Factors}

The cause of Parkinson's disease remains unknown. It appears to result from a complex interaction of genetic and environmental factors affecting many important cellular processes. However, no environmental cause of Parkinson disease has been confirmed. Presently identified genetic factors of Parkinson disease explained about $10 \%$ of the genetic causes of the disease (Hauser et al., 2014). Some of the environmental risk factors include chronic pesticide exposure, prior head injury, chronic use of beta-blocker etc. while some of the genes involved as genetic risk factors include beta-glucocerobrosidase gene (GBA), leucine-rich repeat kinase 2 (LRRK2) gene and synuclein alpha gene (SNCA). Mutations in some of these genes may cause development of Lewy bodies (Kalia and Lang, 2015). The LRRK2 mutations are the most frequent cause of genetic Parkinson's disease, found in about $4 \%$ of familial Parkinson's disease and $1 \%$ of sporadic disease. Mutations in parkin are the most common cause of autosomal recessive Parkinson's disease. In patients with Parkinson's disease onset before age 45 years. Parkin mutations may occur in about $50 \%$ of familial cases and about $15 \%$ of sporadic cases (Jankovic et al., 1990; Corti et al., 2011). However, the highest genetic risk factor for the development of Parkinson's disease is mutation in GBA gene, that codes for beta-glucocerobrosidase, the lysosomal enzyme (Sidransky and Lopez, 2012).

\section{Pathophysiology of Parkinson's Disease}

Parkinson disease is mainly a disorder of the basal ganglia, which are a group of nuclei located at the base of the forebrain. The striatum (consists of the caudate and putamen) is the major nuclear multifaceted of the basal ganglia. There are two main neuropathological discoveries: the damage of pigmented dopaminergic neurons in the substantia nigra pars compacta (SNpc) and the appearance of Lewy bodies. Majority of the cases of Parkinson disease are theorised to be due to the combination of genetic and environmental factors (Hauser et al., 2014).

Alpha-synuclein is present mostly in neuronal presynaptic terminals. It plays a part in the assemblage and function of SNARE (soluble $\mathrm{N}$ ethylmaleimide-sensitive factor activating protein receptor) proteins that are important in the discharge of neurotransmitter. Aberrantly aggregated alpha-synuclein is the main constituent of Lewy bodies (these are intraneural inclusion bodies) that lead to the formation of Lewy neurites, which are typical pathologic outcomes in Parkinson disease (Hauser et al., 2014; Chauhan and Jeans, 2015). Thus, it is due to missense mutations and proliferations in the SNCA gene that encodes alpha-synuclein (See Figure 1). Genome wide association study (GWAS) proved a link between SNCA and sporadic Parkinson disease (Hauser et al., 2014).

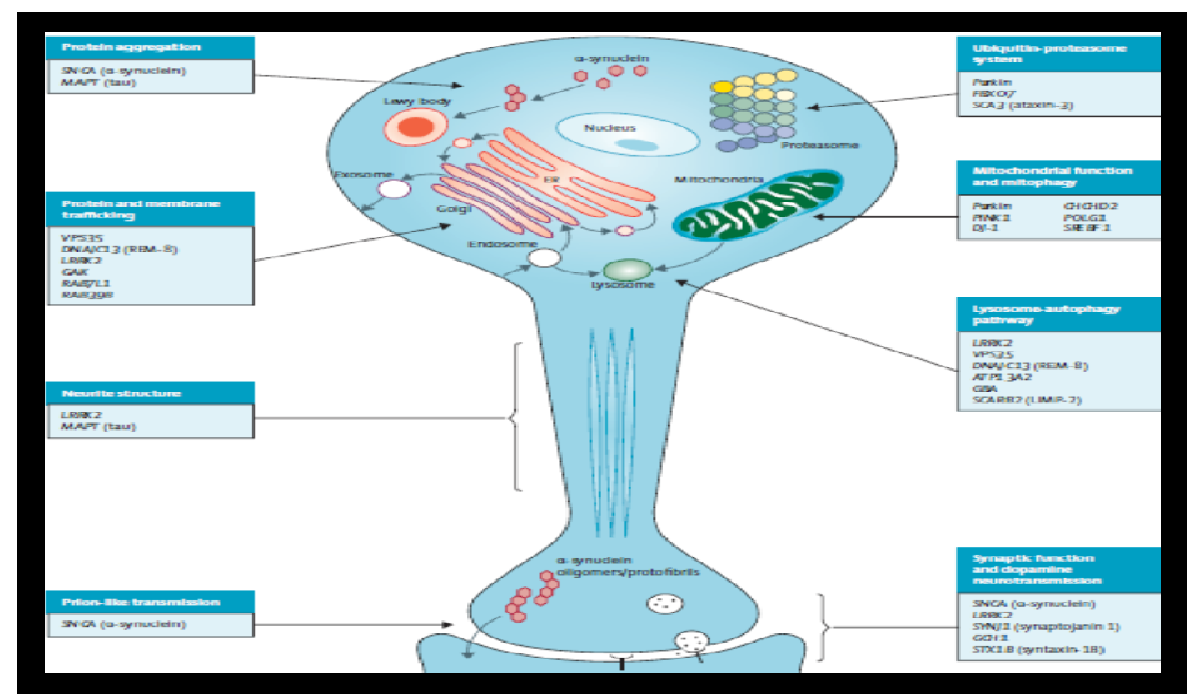

Figure 1: The cellular processes involved in Parkinson `s disease. Source: Kalia and Lang, (2015). 
Furthermore, the oxidation theory proposed that free radical damage, resultant from dopamine's oxidative metabolism, has a significant part in the progress of Parkinson disease. In cases of increase dopamine level from levodopa treatment dopamine is oxidized by monoamine oxidase enzyme (MAO) leading to the generation of hydrogen peroxide. Normally, hydrogen peroxide is removed quickly by glutathione, but if hydrogen peroxide is not sufficiently removed, it can cause generation of extremely reactive hydroxyl radicals, which are able to interact with lipid molecules within the cell membrane leading to lipid peroxidation and cell destruction. Parkinson disease is related to elevated level of dopamine, low defensive measure (glutathione), raised iron (a prooxidation molecule), and indication of excessive cell membrane lipid breakdown. The theory has shown that elevated dopamine level from levodopa treatment can raise oxidative damage and hasten the damaging effect of dopaminergic neurons. However, no strong indication proving that levodopa hastens the disease progress. (Hauser et al., 2014). Moreover, exposure to 1-methyl-4-phenyl-1, 2, 3, 6-tetrahydropyridine (MPTP) for a long duration may cause development of classical features of Parkinson's disease. This is because it traverses blood brain barrier and oxidized to 1-methyl-4-phenylpyridinium (MPP+) by monoamine oxidase, which then collects in the mitochondria and cause mitochondrial toxicity (Ballard et al., 1985). Chemicals like herbicides and pesticides were proposed to behave like this compound however, no particular chemical recognized (Hauser et al., 2014). According to Braak's hypothesis, in Parkinson disease, synuclein pathology commences at the inferior aspect of brainstem and olfactory bulb, rises up to the midbrain, and finally have emotional impact on the neocortex (Chauhan \& Jeans, 2015; Kalia and Lang, 2015). The substantia nigra of Parkinson's disease patient looks darker due to the damage of the dopaminergic neurones (See Figure 2).

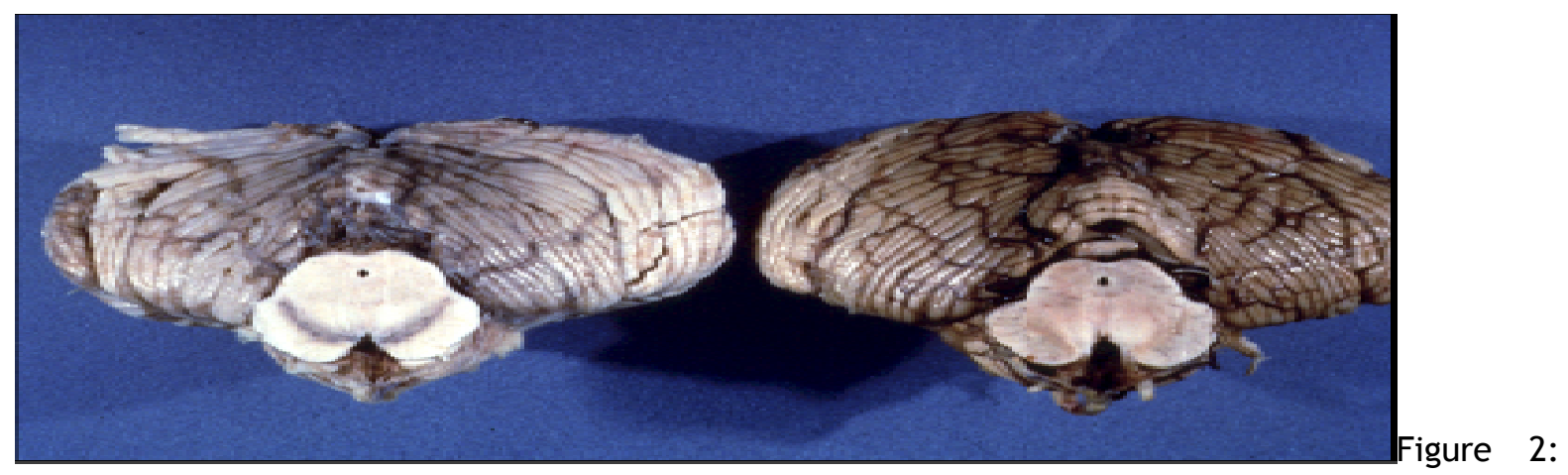

A comparison in appearance of substantia nigra between a normal brain (lighter) and the brain affected by Parkinson disease (darker). Source: Hauser et al., (2014).

\section{Management of Parkinson's Disease}

The management comprises of diagnosis and treatment. The diagnosis is mainly clinical while the treatment is essentially medical.

Diagnosis

Diagnosis involves clinical presentation and investigations. The clinical presentation of the disease starts with non-motor features occurring for a long period before the onset of classical motor symptoms. These non-motor symptoms are also referred to as prodromal symptoms and they include; constipation, rapid eye movement sleep behaviour disorder (shouting, kicking, laughing and sitting up on bed), excessive day sleepiness, decrease sensation of smell (hyposmia), depression, fatigue and mild cognitive impairment $(\mathrm{MCl})$.
The motor symptoms comprise of bradykinesia, which is slowness in initiation of movement. Tremor at rest, rigidity as well as gait and balance problems. Others are dysphagia, postural instability, urinary problems, sexual dysfunction and finally psychosis (Kalia and Lang, 2015, Hauser et al., 2014, Fernandez, 2012).

Some of the investigations include Positron emission tomography and single photon emission computed tomography (PET/SPECT). They can be used to identify the abnormal hyper-dense areas of the presynaptic dopaminergic terminals within the striatum. Scan without Evidence of Dopaminergic Deficit (SWEDD) is useful in newly diagnosed patients with the disease (Kalia and Lang, 2015). 


\section{Treatment}

The aim of medical treatment in Parkinson disease is to offer control of clinical features of the disease as much as possible while lessening side effects of medications. Generally, the drugs act by counteracting deficiency of dopamine in basal ganglia or by blocking the muscarinic receptors. However, none of the drugs improves the underlying neurodegeneration. (Rang et al., 2016)

At present, the main drugs for treatment of Parkinson's disease include but not limited to Dopamine precursor e.g., levodopa. It enters the brain where it is converted to dopamine, which is the deficient neurotransmitter. Levodopa is combined with DOPA-decarboxylase inhibitors (e.g. carbidopa, benserazide) and catechol-O-methyl transferase inhibitors (e.g. entacapone, tolcapone) to prevent peripheral inactivation of levodopa before reaching the brain. Catechol-0-methyl transferase inhibitors and Monoamine oxidase B inhibitors (Selegiline, Rasagiline and safinamide) prevent inactivation of levodopa in the brain to enhance the dopaminergic activity in the substantia nigra. Dopamine agonists (Pramipexole, ropinirole, rotigotine and bromocriptine) act directly by stimulating dopamine receptors in the striatum (Rang et al., 2016; Young and Mendoza, 2018) (See Figure 3). Orphenadrine is a muscarinic receptor antagonist that is useful in the management of Parkinsonism induced by antipsychotic medications (Rang et al., 2016). Antiviral agent e.g. amantadine is also useful in the management of Parkinson disease (Young and Mendoza, 2018).

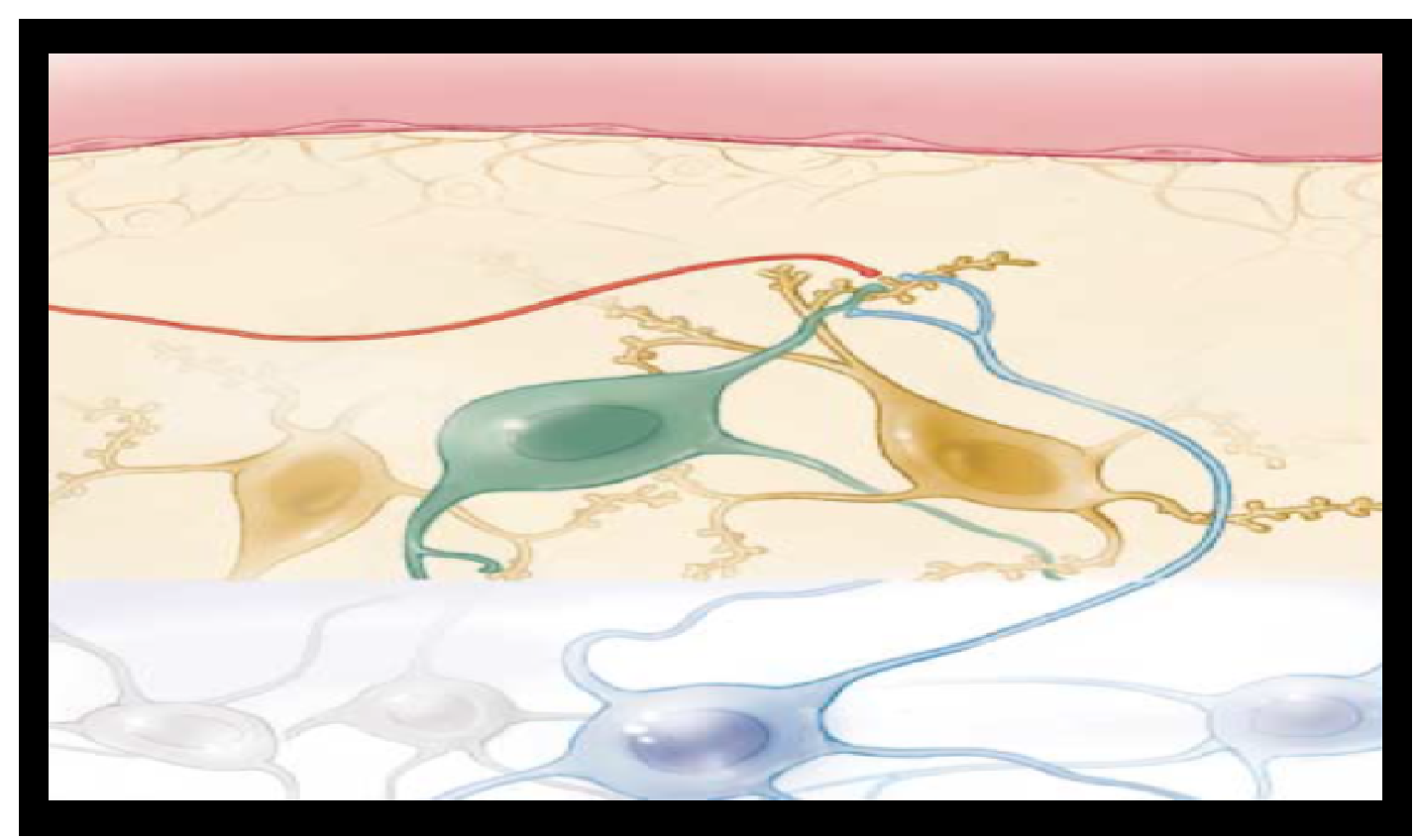

Figure 3: Description of sites of action of drugs used in Parkinson's disease. Source: Connolly and Lang, (2014).

From the figure above, the upper layer is the blood vessel, middle layer is the striatum and the lower layer is the substantia nigra.

Administration of the above-mentioned drugs can be inform of either monotherapy or combination therapy. Dopamine precursor is considered as the first line agent, dopamine agonists and monoamine oxidase inhibitors as the second line agents, while antiviral agent as the third line respectively (See Table 1). 
Table 1: Various Various drug treatments of Parkinson's disease and their side effects.

\begin{tabular}{|c|c|c|c|c|c|}
\hline & Class & & Agent & Use & Side effects \\
\hline First line & $\begin{array}{l}\text { Dopamine } \\
\text { precursor }\end{array}$ & & Carbidopa/levodopa & $\begin{array}{l}\text { Monotherapy to treat } \\
\text { bradykinesia, postural } \\
\text { instability, } \\
\text { and rigidity }\end{array}$ & $\begin{array}{l}\text { Orthostatic } \\
\text { hypotension, } \\
\text { dizziness, headache, } \\
\text { depression, } \\
\text { dyskinesia }\end{array}$ \\
\hline \multirow[t]{2}{*}{ Second line } & $\begin{array}{l}\text { Dopamine } \\
\text { agonist }\end{array}$ & & $\begin{array}{l}\text { Pramipexole, } \\
\text { Ropinirole. }\end{array}$ & $\begin{array}{l}\text { Monotherapy } \\
\text { adjunct to } \\
\text { levodopa to treat } \\
\text { bradykinesia, } \\
\text { postural instability, } \\
\text { and rigidity }\end{array}$ & $\begin{array}{l}\text { Orthostatic } \\
\text { hypotension, } \\
\text { drowsiness, } \\
\text { dizziness, insomnia, } \\
\text { abnormal } \\
\text { dreams, nausea, } \\
\text { constipation }\end{array}$ \\
\hline & $\begin{array}{l}\text { Monoamine } \\
\text { oxidase } \\
\text { inhibitors }\end{array}$ & B & $\begin{array}{l}\text { Selegiline, Rasagiline } \\
\text { and } \\
\text { (Safinamide Safinamide } \\
\text { approved recently in } \\
\text { 2017). }\end{array}$ & $\begin{array}{l}\text { For off-label use as } \\
\text { monotherapies or } \\
\text { adjunctive therapies } \\
\text { with } \\
\text { carbidopa/levodopa. }\end{array}$ & $\begin{array}{l}\text { Headache, dizziness, } \\
\text { insomnia, nausea, } \\
\text { hypotension. } \\
\text { Safinamide can cause } \\
\text { increase levels of } \\
\text { liver enzymes }\end{array}$ \\
\hline Third line & Antiviral & & Amantadine & $\begin{array}{l}\text { Monotherapy } \\
\text { adjunctive } \\
\text { Therapy. }\end{array}$ & $\begin{array}{l}\text { Orthostatic } \\
\text { hypotension, } \\
\text { syncope, peripheral } \\
\text { oedema. } \\
\text { Avoid use } 2 \text { weeks } \\
\text { before and } \\
2 \text { weeks after live } \\
\text { influenza } \\
\text { vaccine }\end{array}$ \\
\hline
\end{tabular}

Source: Young and Mendoza, (2018).

\section{Complications}

Some of the complications of the disease include Fluctuations of motor symptoms and non-motor symptoms, dyskinesia and psychosis e.g. hallucinations and delusions (Kalia and Lang, 2015). The risk of frequent fall was estimated to be three (3) times compared to healthy individuals $(\mathrm{P}<0.001)$ among Parkinson's disease patients of Nigerian population (Farombi et al., 2016).

\section{CONCLUSION}

It is concluded that Parkinson's disease is a neurodegenerative disorder characterized by non-motor symptoms for a long period before the onset of classical motor symptoms. The aetiology of the disease comprises of genetic and environmental factors. Both male and female may be affected especially at elderly stage. Aberrantly aggregated alpha-synuclein is the main constituent of Lewy bodies that lead to Lewy neurites and pathologic outcome. The disease is associated with morbidity and mortality. Therefore, strategies to increase life expectancy should involve prevention of motor progression and development of psychotic symptoms as early as possible. Diagnosis is mainly clinical and treatment is essentially medical which include dopamine precursor e.g. Levodopa in combination with carbidopa as the mainstay for control of motor symptoms. Others are dopamine agonists and monoamine oxidase inhibitors etc. However, the treatment has no significant effect on neurodegeneration.

\section{RECOMMENDATIONS}

The following are recommendable as possible way forward to the diagnosis and management of Parkinson's disease:

- Suspected individuals older than 60 years should be examined by Neurophysicians to rule out early features of Parkinsonism.

- Any abnormal behavior or evidence of cognitive impairment in elderly individuals should be investigated properly to prevent delay in making early diagnosis.

- Environmental risk factors such as chronic pesticide exposure should be reduced as much as possible.

- Various biomarkers to be used in different parts of the body for the identification of possible aetiological risk factors of the disease should be developed.

- Early treatment of diagnosed patients should be considered in confirmed cases of Parkinson's disease to avoid development of severe complications. 


\section{REFERENCES}

Ballard, P. A., Tetrud, J. W., and Langston, J. W. (1985). Permanent human Parkinsonism due to 1-methy 14-phenyl-1, 2, 3, 6-tetrahydropyridine (MPTP) Seven cases. Neurology, 35(7), 949-949.

Chauhan, A., and Jeans, A. F. (2015). Is Parkinson's disease truly a prion-like disorder? An appraisal of current evidence. Neurology international, 2015. 2

research

Connolly, B. S., and Lang, A. E. (2014). Pharmacological treatment of Parkinson disease: a review. Jama, 311(16), 16701683.

Corti, O., Lesage, S., and Brice, A. (2011). What genetics tells us about the causes and mechanisms of Parkinson's disease. Physiological reviews, 91(4), 1161-1218.

De Lau, L. M., and Breteler, M. M. (2006). Epidemiology of Parkinson's disease. The Lancet Neurology, 5(6), 525-535.

Driver, J. A., Logroscino, G., Gaziano, J. M., and Kurth, T. (2009). Incidence and remaining lifetime risk of Parkinson disease in advanced age. Neurology, 72(5), 432-438.

Farombi, T. H., Owolabi, M. O., and Ogunniyi, A. (2016). Falls and Their Associated Risks in Parkinson's disease Patients in Nigeria. Journal of movement disorders, 9(3), 160.

Fernandez, H. H. (2012). Updates in the medical management of Parkinson disease. Cleve Clin J Med, 79(1), 28-35.

Forsaa, E. B., Larsen, J. P., Wentzel-Larsen, T., and Alves, G. (2010). What predicts mortality in Parkinson disease? A prospective population-based long-term study. Neurology, 75(14), 1270-1276.
Hauser, R. A., Benbadis, S. R., Lyons, K. E., McClain, T. A., and Pahwa, R. (2014). Parkinson Disease, Medscape. Updated June 2018.

Jankovic, J., McDermott, M., Carter, J., Gauthier, S., Goetz, C., Golbe, L., and Stern, M. (1990). Variable expression of Parkinson's disease. A base-line analysis of the DAT ATOP cohort. Neurology, 40(10), 1529-1529.

Kalia, L.V., and Lang, A.E. (2015). Parkinson Disease seminar. 386: 896-912.

Okubadejo, N. U., Ojo, O. O., and Oshinaike, O. O. (2010). Clinical profile of Parkinsonism and Parkinson's disease in Lagos, Southwestern Nigeria. BMC neurology, 10(1), 1.

Postuma, R. B., Aarsland, D., Barone, P., Burn, D. J., Hawkes, C. H., Oertel, W., and Ziemssen, T. (2012). Identifying prodromal Parkinson's disease: pre-motor disorders in Parkinson's disease. Movement Disorders, 27(5), 617-626.

Pringsheim, T., Jette, N., Frolkis, A., and Steeves, T. D. (2014). The prevalence of Parkinson's disease: A systematic review and meta-analysis. Movement disorders, 29(13), 1583-1590.

Rang, H. P., Ritter, J. M., Flower, R. J., and Henderson, G. (2016). Rang and Dales Pharmacology 8th. Elsilver Co., London.

Sidransky, E., and Lopez, G. (2012). The link between the GBA gene and Parkinsonism. The Lancet Neurology, 11(11), 986-998.

Young, J., and Mendoza, M. (2018). Parkinson's disease: A treatment guide. The Journal of family practice, 67(5), 276279. 